\title{
Strategies of pro-EU parties in the face of a Eurosceptic challenge
}

\section{Introduction}

During the last decade, almost all countries within the EU have experienced the emergence of Eurosceptic parties. These parties have won 113 out of 751 seats in the 2014 European Parliament elections. Their unprecedented success was fuelled by the ongoing crisis of the EU regarding bailout, the threat of a Eurozone breakdown, growing state debts, the instability of the banking system and disputed austerity measures. Thus, Eurosceptic parties have become a challenge for those parties that have integrated Europe for decades.

This article seeks to describe how pro-European parties strategically communicate when facing this Eurosceptic challenge and how this affects the politicization of EU integration in each of the examined countries. Our description of pro-European parties' strategic behaviour grants special attention to pro-European catch-all parties, especially to those struggling with internal dissent regarding EU integration, as it is these large, vote-winning parties that strongly shape societal debates.

Our study contributes to research in a three-fold manner. First, we focus on the strategic interactions of parties (for this research desiderate, e.g. Kriesi, 2008) by analysing how pro-EU parties communicate when facing a Eurosceptic challenge. In this analysis we depart from research focusing predominantly on Eurosceptics. Instead, Eurosceptic parties in our study serve as a comparative baseline to identify the strategies of pro-EU parties. Second, drawing on Meguid (2005) and Bale et al. (2010), we further elaborate on the strategic repertoire that parties have at hand. Third, we link strategic party behaviour to EU politicization in a country. We thereby show that parties' communication strategies regarding topics, issues and positions 
directly affect the core components of politicization. Politicization within a country occurs if (a) salience is attached to the topic of EU integration; (b) parties enter a common debate about the same aspects of EU integration and (c) polarized opinions are voiced.

Our focus on party elites' strategic behaviour and the resulting elite politicization towards EU integration seems justified as research has shown that it is elites who (partially) shape public opinions about EU integration (Gabel and Scheve, 2007), who impact the extent to which voters rely on EU considerations in European Parliament elections (Hobolt and Spoon, 2012) and who strongly influence mass media coverage about the integration project (Adam, 2007).

To answer our research question on the communication of pro-European parties when facing a Eurosceptic challenge, we first describe the strategic repertoire that pro-European parties have at hand and develop hypotheses on how this repertoire is used by pro-European parties in general and by pro-European catch-all parties facing strong internal dissent. Second, we illustrate how party strategies can be analysed by means of quantitative content analysis of press releases in the run-up to the 2014 EP elections in seven countries (Austria, France, Germany, Greece, the Netherlands, Portugal and the United Kingdom) and operationalize relevant party classifications based on secondary data. In a third step, we present the results concerning parties' strategic behaviour in the run-up to the 2014 elections. We then show how these strategic decisions influence a country's politicization.

\section{Party strategies in the face of a Eurosceptic challenge}

The general assumption backed by empirical support is that Eurosceptic parties challenge proEuropean parties by putting new issues and new positions regarding the EU (namely negative evaluations) on the agenda to 'upset the dominant party alignment' (Carmines and Stimson, 1993: 154; for empirical evidence, e.g. Hooghe and Marks, 2008; Parsons and Weber, 2011). 
However, as research has shown that no party has monopolistic agenda control (e.g. Adam and Maier, 2016; Steenbergen and Scott, 2004), pro-European parties have to make strategic decisions regarding how to respond.

\section{Pro-EU parties' strategic repertoire}

Two dimensions of parties' strategic decisions are distinguished in the literature (GreenPedersen, 2007). First, parties have to decide which issues to emphasize, e.g. whether to stress immigration or the welfare state (Budge and Farlie, 1983; Petrocik, 1996). Second, they have to decide which positions to make salient (Downs, 1957), meaning that they side, for example, with a state that promotes public welfare to a lesser or greater degree. However, whenever we deal with multi-dimensional topics_-one of the most prominent examples being EU integration (Green-Pedersen, 2011; Hurrelmann, Gora and Wagner, 2013) - it is not sufficient to distinguish two dimensions of party strategies as proposed in the literature. The topic of EU integration consists of a multitude of different issues: immigration, the economy, foreign affairs and constitutional questions (to name just a few) can all be discussed with reference to EU integration. As a consequence, we propose to differentiate the emphasis dimension of strategic party communication. First, a party strategically decides whether it makes reference at all to the broader topic of EU integration. Second, a party then selects specific aspects within the broader topic of EU integration. We label these aspects issues. They indicate whether a party gets involved in debates about, for example, immigration, austerity measures or foreign affairs in relation to EU integration. A party thereby strategically decides not only about the issue discussed but also whether to mention that it is related to the EU. We regard this distinction as crucial as it allows us to understand not only to which degree parties put Europe on the agenda, but also whether by doing so they enter a common debate or talk past each other as every party selectively emphasizes issues that are advantageous to itself (e.g. Petrocik, 1996). 
Based on these considerations, we conceive a three-dimensional strategy repertoire of parties consisting of a topic, an issue and a position dimension.

For each dimension, pro-EU parties have to decide on the specific strategies they wish to employ. For the topic dimension, parties have to decide whether they want to emphasize the broader topic of EU integration at all or strategically decide to refer to the nation state. We call the former strategy an 'agenda-building strategy', whereas the latter is labelled a 'silencing strategy'. If pro-EU parties employ agenda-building strategies, they must then make decisions about the issue as well as the position.

Concerning the issue dimension, pro-EU parties have two options: they may either try to shift the debate towards those issues of EU integration from which they can profit and thus raise EU issues distinct from those raised by Eurosceptic parties ('strategy of distinct issue emphasis'), or they emphasize issues similar to those raised by the Eurosceptics in order to prevent Eurosceptics from monopolizing sensitive issues ('strategy of similar issue emphasis').

Finally, for the position dimension, pro-EU parties have three strategic options: they may defend their pro-EU position consistent with the traditional party line ('hold strategy'); leave their position and adopt EU-critical stances of Eurosceptic parties ('adoption strategy') or blur their position towards the EU by either avoiding to formulate positions at all or by formulating ambivalent statements ('blurring strategy'). ${ }^{1}$

Figure 1 visualizes pro-EU parties' strategic repertoire based on the aforementioned three dimensions (topic, issue and position) containing seven strategic choices. The figure makes clear that as soon as an agenda-building strategy has been chosen for the topic dimension, different strategic choices can be combined. 
\# Figure 1 about here \#

This three-dimensional strategic party repertoire partly mirrors the strategic options which have been ascribed to pro-European parties to meet the Eurosceptic challenge (Bale et al., 2010; Meguid, 2005): pro-European parties may either opt for silencing strategies shifting attention to national topics or they may turn into topic followers. As such, they may mimic the Eurosceptics' position resulting in adoption strategies or they may defend their own pro-EU positions. These four strategies identified in the literature deal with both the topic and positional level of our strategic party repertoire. We have extended this strategic repertoire in a two-fold manner: first, by bringing in the idea of position blurring, we have added an important positional strategy which allows parties 'to misrepresent the distance between the party and its potential voters' (Rovny, 2012: 273). Second, adding the issue level opens up two additional strategic options for parties, i.e. the distinct or similar issue emphasis. This new dimension allows us to show whether parties talk past each other or not.

\section{Hypotheses and research question regarding pro-EU parties' strategic repertoire}

We first turn to the topic dimension of parties' strategic choices. Pro-EU parties have been shown to often apply silencing strategies, whereas Eurosceptics act as agenda-setters (e.g. Hooghe and Marks, 2008; Parsons and Weber, 2011) for at least three reasons: (1) pro-EU parties often struggle with internal party disagreement on EU integration (Ferrara and Weishaupt, 2004); (2) they fear losing voters who are normally mobilized on a left-right dimension (Eijk and Franklin, 2004) and (3) they are afraid of losing control over their campaign agenda due to the multidimensionality of EU integration (Green-Pedersen, 2011). Consequently, we expect: 
H1a: Pro-European parties rely more strongly on silencing strategies regarding the topic of EU integration compared to Eurosceptic parties.

However, this divide between Eurosceptics and pro-European parties in setting Europe on the agenda has recently been shown to depend on the degree of dissent about Europe within proEuropean governing parties (van de Wardt et al., 2014): if pro-European governing parties are internally united on the topic of EU integration, Eurosceptic opposition parties refrain from bringing it up and the governing parties turn into agenda-builders. It is only if dissent prevails within pro-European government parties that these parties de-mobilize and Eurosceptics use the issue to exploit the cracks. The article extends this argument to catch-all parties in general since all of them (as well as those in opposition) are not only likely to take over government responsibility but, due to their heterogeneous party base, are also more likely to face internal dissent compared to smaller pro-European parties (for the relevance of party size, see Williams and Spoon, 2015). Beyond, such parties are crucial for shaping the overall societal debate. Consequently, it is catch-all parties (in government and opposition) whose cracks are potentially exploited by Eurosceptic parties and whose own communication is guided by their internal dissent. We expect:

H1b: Pro-EU catch-all parties with strong internal dissent rely more strongly on silencing strategies regarding the topic of EU integration compared to internally united catch-all parties.

Less is known about the question whether pro-EU parties emphasize their own selective issues regarding EU integration or whether they campaign on the same issues as Eurosceptic parties. In earlier years, researchers have claimed that parties in all elections talk past each other-each of them emphasizing the issues on which they are judged competent (Petrocik, 1996). However, more and more research questions the general validity of the selective em- 
phasis thesis (e.g. Green-Pedersen and Mortensen, 2010; Sigelman and Buell, 2004). Rather, it seems that parties observe their issue environments and react accordingly. Discussing the same issues as other parties is very important for the following reasons: parties are expected to have a position on all issues. Furthermore, ignorance of an issue implies that they pass on shaping the positional struggle (Green-Pedersen and Mortensen, 2010), and they run the risk of being accused of inactivity (Van Noije et al., 2008). As research has produced evidence that parties emphasize their own as well as shared issues in election campaigns in general and, to our knowledge, there is no such study that has analysed this question in the course of EP elections, we refrain from formulating hypotheses but instead pose the following research question: Do pro-European parties employ a strategy of emphasizing distinct or similar issues in reaction to Eurosceptic parties?

Finally, hardly any research has been conducted regarding pro-EU parties' decisions to hold or shift their position when dealing with the Eurosceptic challenge. Some first evidence, however, points towards the predominance of hold strategies. Looking at campaign material in EP elections, Adam et al. (2013) found that pro-EU parties advance their positions most forcefully in those countries in which Eurosceptics voice strong criticism. Bale et al. (2010) stress the difficulty and danger of adoption strategies towards the populist right. The relevance of hold strategies is also underlined by De Sio and Weber (2014) who claim that position change ('adoption strategy') is a costly strategy for parties likely to result in alienating voters. As a consequence, we expect:

H2a: Pro-European parties choose hold strategies over adoption strategies and thus voice positions that are distinct from those of Eurosceptic parties.

However, forcefully defending their pro-European positions might be especially challenging for those pro-European parties that face strong internal dissent on matters of EU integration as 
this elite dissent is likely to be reflected in the electorate of a party. In this case, clear-cut proEuropean positions might alienate part of the electorate. As a consequence, parties may adhere to two positional strategies: first, they may avoid making dissent visible at all, which results in blurring strategies, i.e. the avoidance of EU evaluations or the formulation of ambivalent statements. Second, it is also such internally divided parties for which the likelihood of adoption strategies increases (compared to internally united parties). Adoption strategies occur if a party judged pro-European by experts publicly communicates only 'lukewarm' support or anti-EU positions.

Adoption strategies thus do not necessarily require a black-white divide of a party's position and its communication. A position-wise clear-cut pro-European party can instead take up parts of the Eurosceptic rhetoric and combine it with traditional pro-European stances on other issue fields in other parts of its public communication. By doing this, it already applies adoption strategies as it departs from its attributed pro-European party line (as judged by experts) communicating only 'lukewarm' support. We thus expect:

$H 2 b$ : Pro-European catch-all parties with strong internal dissent are more likely to choose adoption and blurring strategies compared to internally united catch-all parties.

\section{Parties' strategies as shapers of a country's EU politicization}

Pro-European parties' strategic behaviour affects the degree and form of the EU's elite politicization in each country. Generally speaking, politicization is a process that results in public debate about a political issue. In the last decade an abundant literature has focused on politicization processes and their outcomes, in particular related to the European Union (e.g. Koopmans and Statham, 2010; Kriesi et al., 2008; Hutter and Grande, 2014). Our starting point is De Wilde's (2011: 566f.) definition of politicization as 'an increase in polarization of opinions, interests or values and the extent to which they are publicly advanced towards poli- 
cy formulation within the EU'. From this perspective, EU politicization has three characteristics: the large range of opinions voiced, their visibility and their relevance for policy formulation. Policies are normally formulated as answers to specific issues, i.e. societal conflicts about specific policy questions. We thus conclude that to make (contrasting) opinions relevant for policy formulation, they should be voiced in the same issue area. It is only if parties share a common issue focus that the various opinions voiced can be meaningfully connected to each other. EU politicization thus means that (a) a large range of opinions is voiced regarding EU integration; (b) that these opinions are meaningfully related because they focus on the same issues and (c) that they become visible (also see Hutter and Grande, 2014).

The main contribution to the politicization literature is that we link EU politicization to its strategic and behavioural origins. In this vein, topic visibility, issue focus and range of opinions are not only the crucial components of elite politicization but also the crucial dimensions of party strategies. Full politicization, therefore, requires that actors (a) avoid silencing strategies, (b) are willing to emphasize similar issues (strategy of similar issue emphasis) and (c) that pro-EU parties choose hold strategies voicing opinions that contradict those of the Eurosceptics. Politicization in this respect becomes the aggregate outcome of actors' strategic decisions regarding topics, issues and positions.

\section{Data, Operationalizations and Methods}

To study parties' strategies and the resulting politicization, we focus on parties' campaign communication in the run-up to the 2014 EP elections in seven countries, namely Austria, France, Germany, Greece, the Netherlands, Portugal and the United Kingdom. We have chosen these countries because they are all confronted by the Eurosceptic challenge as indicated by expert judgments of party stances on EU integration in the Chapel Hill Expert Survey (CHES) collected for the year 2014 (Bakker et al., 2015). All parties that score below 3 on a 
scale from 1 to 7 were rated as Eurosceptic (see the online appendix), while pro-European parties are all rated above 5 on the EU integration scale. These countries also vary in the degree of dissent among pro-European catch-all parties, which are defined as all parties that won more than 20 percent in the last national election and have a clear-cut pro-EU stance. However, two of these large parties - the British Conservatives and Syriza in Greece (see the online appendix) - must be regarded as border-line cases since they are neither clear-cut pro- nor anti-European. To study the degree of dissent on EU integration, we rely on CHES data where each party was classified by experts regarding their degree of internal dissent.

For the analysis of parties' strategic communication, we rely on press releases. We chose press releases over other traditional means of party communication (e.g. parliamentary questioning, manifestos) for three reasons: first, they are quite independent from fixed schedules (e.g. parliamentary questionings) and other external events and thus allow the direct observation of a party's strategic behaviour; and second, they are instruments geared towards the media and thus allow the observation of a party's public instead of internal (e.g. manifestos) communication. Finally, we opted for press releases instead of any forms of online campaign communication because parties still vary considerably regarding their online activity (Stetka, Lilleker, Tenscher and Jalali, 2014).

We considered all press releases issued by parties that participated in the 2014 EP elections and won at least three percent of the votes in the 2009 EP or the respective last national election. We analysed all press releases twelve weeks preceding the 2014 EP elections. As we are interested in party strategies towards Europe and the resulting EU politicization, we sampled press releases based on an electronic search string ${ }^{2}$ that made reference to European policies, European institutions, European politicians and/or the EP elections at least twice. This search resulted in a total of 936 press releases for Austria, 180 for France, 301 for Germany, 518 for 
Greece, 178 for the Netherlands, 322 for Portugal and 223 for the United Kingdom.

To systematically analyse the content of the press releases, we rely on a quantitative content analysis based on a detailed codebook (Maier et al., 2014). All eight coders mutually participated in a comprehensive eleven-day-long training program followed by a (researcher-coder) reliability test of 25 press releases each to ensure the reliability of coding. We tested for reliability of coding using the Holsti formula as well as Krippendorff's Alpha coefficient whenever possible or useful. With average results for formal categories (e.g. date of publishing, source, country etc.) of $0.98-1.00$ according to the Holsti formula and $0.97-1.00$ according to Krippendorff's Alpha, and reliabilities for content characteristics (e.g. main issue, evaluation of the EU etc.) of $0.77-0.88$ (Holsti formula) and 0.62-0.83 (Krippendorff's Alpha) across the countries, reliability tests delivered satisfactory results. ${ }^{3}$

This content analysis allows us to operationalize topic, issue and positional strategies and the resulting dimensions of politicization. To analyse topic strategies and the resulting visibility of EU integration, we measure the salience that parties attach to EU integration by looking at the amount of EU-related press releases in proportion to all published press releases. To operationalize the issue strategy and the resulting distinct or shared issue focus, we look at the main issue covered in a press release. Altogether, we distinguish 17 issue categories (Maier et al., 2014). Based on the relative frequencies of these issue categories per party, we calculate the Duncan index of dissimilarity for each pair of parties (Duncan and Duncan, 1955). This index takes a value between 0 and 1 , which can be conveniently interpreted as the percentage of a party X's communication that has to be shifted to other issues in order to have an identical issue emphasis as party $\mathrm{Y}^{4}$ To facilitate the interpretation of the results, we subtract the original Duncan dissimilarity index score from 1 . The resulting issue similarity score ranges 
between 0 (= different emphasis) and 1 (= same emphasis) and thus can be interpreted as a distance measure between parties based on their issue emphasis.

For the operationalization of the positional strategy and the resulting range of opinions voiced, we analyse how each party evaluates the general idea of European integration (INTEGEVAL) and how it evaluates the more specific functioning of the EU today, including its institutions, politicians and policies (EUEVAL). Both indicators differentiate between four categories: positive, negative, balanced (as many positive as negative evaluations) and no evaluation. Based on these variables, we derive information on the frequency of EU evaluations and of balanced statements (blurring strategy) and on the evaluation as such (hold or adoption strategies). For the former, we analyse the share of EU-related press releases that contain no clear-cut position on the general idea and / or the more specific functioning of the EU (position not available at all or balanced statement); for the latter, we build one EU evaluation index per party based on those press releases that contain a clear-cut evaluation. This index ranges from -1 (strong Euroscepticism) to +1 (strong EU support). ${ }^{5}$ It should be noted that this index gives more weight to evaluations referring to the idea of European integration in general than to evaluations of specific policies or institutions. To finally identify adoption or hold strategies we compare a party's communication index with its general position on EU integration as judged by experts in the CHES survey (Bakker et al., 2015). We speak of adoption, if a party judged pro-European (neutral towards Europe) applies only 'lukewarm' support or even anti-EU rhetoric in its communication.

We conduct analyses for each country separately, which allows us to describe the strategic choices disaggregated to even single parties. We thereby depart from a classical regression logic which would analyse all parties of all countries together searching for the general effect of party or country characteristics on strategic party behaviour. We have opted for this de- 
tailed description as we aim to show possible heterogeneity within countries and party types. However, this very detailed description of party strategies per country is accompanied by an eschewal of controlling for explanations that go beyond the factors focused on here (namely party position and internal party dissent). Such alternative explanations might either be found on the party level (e.g. electoral success or government participation) or on the country level (e.g. electoral cycle or general issue agenda). We opted for this descriptive approach due to the scope of this article and the small case numbers which are a result of our country-specific strategy of analyses

We apply network methods (e.g. Borgatti, Everett and Johnson, 2013) to these countryspecific analyses. We do so as network analysis was developed to deal with the interrelations between observations instead of regarding them as independent from each other. This is crucial because the core assumption of our article is that parties' strategies within a country are closely intertwined. Thus we claim that pro-European parties are indeed affected by the Eurosceptic challenge.

To apply network analysis, we convert our core variables (position of party towards EU integration; communication regarding topic, issue and EU evaluation) into a dyadic variable (e.g. Borgatti et al., 2013). A dyadic variable does not describe the attribute of a party as such, but rather the difference between each pair of parties. Looking, for example, at the positions of two parties towards EU integration $(\mathrm{A}=1.5 ; \mathrm{B}=6)$, from a dyadic perspective we would ask whether the difference between party A and B (delta $=4.5)$ could explain differences in topic focus. We thus test whether differences of parties regarding their position towards EU integration are related to general differences in (1) parties' topic emphasis, (2) their issue focus and (3) their EU evaluations. To do so, we rely on Quadratic Assignment Procedure (QAP) correlations using the Program UCINET. QAP is designed to correlate dyadic variables calculating 
statistical associations such as Pearson's r. It thereby calculates significance by permutation tests in which it compares the observed correlation with those resulting from thousands of randomly created matrices (e.g. Borgatti et al., 2013) - a method that does not require independent observations.

\section{Results}

Topic dimension: Agenda-building or silencing strategies of pro-EU parties?

To test whether pro-EU parties as such attach less salience to the topic of EU integration (silencing strategies) compared to Eurosceptics (H1), we look at the share of press releases which contain a reference to Europe in relation to all press releases published per party and convert this information into a dyadic relation to test whether differences in parties' EU positions are associated with differences in the salience parties attach to the topic of EU integration.

The QAP correlations shown in Table 1 lead us to reject the idea that pro-European parties as such adhere more strongly to silencing strategies compared to Eurosceptics $(H / a)$. This is indicated by the non-significant results in Table 1. It is only in Germany that pro- and anti-EU parties differ on the topic dimension, with pro-European parties relying more strongly on silencing strategies compared to Eurosceptics (see the online appendix). In Germany it is the newly founded AfD, a Eurosceptic right-wing party, which devotes around 43 percent of their press releases to Europe compared to the other parties that only devote between 20 to 24 percent to the EU.

\# Table 1 about here \# 
The analysis so far merely indicates that there is not a general divide between pro- and antiEU parties on the topic dimension in six out of seven countries. However, this general finding does not preclude the possibility that specific pro-EU parties adhere to silencing strategies. $H 1 b$ assumes that pro-EU catch-all parties with strong internal dissent are more likely to employ silencing strategies compared to united pro-EU catch-all parties. Indeed, a close-up view of our data lends support to this idea. It is not catch-all parties as such, but those that are internally divided that are most likely to employ silencing strategies. Silencing is applied heavily by the divided French catch-all parties (UMP, 9 percent; dissent: 5.8; PS, 15 percent, dissent 6.8), by British parties (Labour: 7 percent, dissent: 3.6, Conservatives [although this party is balanced rather than pro EU], 18 percent, dissent: 7.3), and to a lesser degree by Dutch catch-all parties (VVD, 19 percent, dissent: 4.3; PvdA, 23 percent, dissent: 5.0), the Greek party Syriza (23 percent, dissent: 7.1) and by German parties (CDU/CSU and SPD, both 23 percent, dissent 3.2 and 2.8). With the exception of German parties, all of these catch-all parties experience quite substantial amounts of internal dissent about EU integration.

Pro-EU catch-all parties that do not use silencing strategies were only found in three of the analysed countries, namely Austria, Greece and Portugal. Interestingly, the mobilizing parties (with the exception of the Portuguese Partido Socialista) are strongly united on the question of EU integration. In Austria, the two leading catch-all parties mention Europe in 41 percent (ÖVP, dissent: 1.9; SPÖ, dissent: 2.8) of their press releases, and together with the Eurosceptic BZÖ they are the leading EU mobilizers. Interestingly, the large Eurosceptic FPÖ mentions Europe in only 28 percent of their press releases. In Portugal, the large parties are among the strongest mobilizers on EU-related topics (Aliança Portugal: 61 percent, dissent: 2.7, Partido Socialista: 42 percent, dissent: 3.7). Finally, in Greece, it is the Conservative Nea Dimokratia (ND, dissent: 2.6) that belongs to the strongest EU agenda-setters (41 percent) 
whereas the internally divided Syriza, the second catch-all party in Greece, which experts rated as balanced in reference to EU integration, only has a share of 23 percent.

\section{Issue dimension: Distinct or similar issue emphasis of pro-EU parties?}

To study whether pro-European parties emphasize their own EU-related issues or share common issues with Eurosceptics, we rely on the Duncan index of similarity. High values on this index indicate that two parties debate similar issues, whereas low values show distinct issue foci. To test whether pro- and anti-EU parties as such differ in their issue emphasis, we rely on QAP correlations and ask if differences in party positions (indicated by high values) are associated with differences in issue emphasis (indicated by low values). Negative correlations thus show that pro- and anti-EU parties talk past each other.

Table 2 indicates country differences. In five countries (AT, F, GR, UK, PT) party positions are not related to issue emphasis, which means that pro- and anti-EU parties are not systematically separated by their focus on different issues. In Germany and the Netherlands, pro- and anti-EU parties put different issues on their agendas and thus talk past each other, as indicated by the negative significant correlations.

\# Table 2 about here \#

As the results so far only indicate that in most countries there is no general divide between pro- and anti-EU parties issue-wise, they do not show which parties put the same and which parties put distinct issues on the agenda. To obtain this information, we use the Duncan index as a distance measure between parties, visualizing it with a network algorithm that draws the parties close to each other that emphasize similar issues and separates those parties that have distinct issue foci (force atlas II, Gephi). Figure 2 reveals three groups of countries. In the first 
group composed of Germany and the Netherlands, pro-EU parties as such (as also shown by QAP correlations) emphasize different issues compared to Eurosceptics. A second group consists of Austria, Greece and Portugal. In these countries we find common issue emphasis in all parties (with the exception of the nationalists in Greece [XA]). Finally, the United Kingdom and France constitute a third group. In these countries, pro-EU catch-all parties emphasize issues similar to those emphasized by Eurosceptics, whereas smaller pro-EU parties are pushed to the margins. For the UK, this results in a constellation in which the Conservatives and the Labour party campaign on issues similar to those adopted by UKIP and BNP, whereas the Greens and the Liberal Democrats put different issues on the agenda. Summing up, we see that most pro-European catch-all parties (those with strong and weak internal dissent) hardly avoid the topics of the Eurosceptics. Pro-European catch-all parties keep their distinct issue foci in only two countries.

\# Figure 2 about here \#

\section{Position dimension: Hold, adoption or blurring strategies of pro-EU parties?}

To test whether pro-EU parties actually choose hold over adoption strategies, in other words if EU support outweighs EU critique in their public communication (H2a), we use the EU evaluation index. This index is based on our content analysis data and ranges from -1 (strong Euroscepticism) to +1 (strong EU support). We expect that those parties which are rated as having similar EU positions by experts (CHES data) also express similar EU evaluations in their public EU communication, i.e. that pro- (anti-) EU parties communicate in support of (in opposition to) the EU. This relationship is indicated by positive QAP correlations.

The results shown in Table 3 support the idea that pro- and anti-EU parties differ in their EU communication, i.e. that similarity of party positions as judged by experts is accompanied by 
similarity in voiced EU positions in our content analysis data. This is indicated by positive, statistically significant QAP results in six out of seven countries. A closer look at the data supports our expectation that Eurosceptics express more criticism than pro-EU parties which, in sum, is a strong indicator for the prevalence of hold strategies $(H 2 a)$. But there is one disturbing result: a negative moderate correlation in Portugal, which indicates that similarity in positions judged by experts is not reflected in similarity in public communication. Portugal appears to be a particular case as all parties here strongly support the EU in their public communication - even though the CDU was rated as EU-critical by experts in the CHES survey (Bakker et al., 2015).

\section{\# Table 3 about here \#}

Nevertheless, three objections must be examined in more detail. First, so far we only know that pro- and anti-EU parties differ in their public EU evaluations, but we do not know to what extent (i.e. do all of them criticize (support) EU integration more or less strongly?). Figure 3 shows the range of positions voiced in the seven countries included in the study. This figure demonstrates that clear-cut pro-European positions are voiced by at least one party in five of our seven countries (AT, F, GER, PT, UK), whereas in two countries, Greece and the Netherlands, pro-European positions only receive lukewarm support and Eurosceptic positions are forcefully put forward. We thus see tendencies for adoption in Greece and the Netherlands.

\# Figure 3 about here \# 
Second, although we can show that similarity in party positions judged by experts coincides with similarity in public communication, this association is far from perfect (e.g. in Greece), which leaves room for single parties' adoption strategies. A closer look at pro-European catch-all parties shows that some of them adhere to adoption strategies. These parties either openly criticize EU integration even though they are judged balanced by experts (Syriza, GR: -0.28) or they show only 'lukewarm' support even though they are classified as clearly proEuropean by experts (VVD, NL: 0.05; Labour, UK: 0.06).

Third, pro-European parties have another strategic option, blurring, which does not show up in the evaluation index. Blurring is defined here as the avoidance of EU evaluations or as the formulation of balanced statements from which no clear-cut EU evaluation can be derived (for the results, see the online appendix). Among our pro-European catch-all parties, we can identify four that strongly adhere to blurring strategies: the French UMP which avoids any EU evaluation at all; the Conservatives in the UK which evaluate the EU in only $33 \%$ of their EUrelated press releases and the two Greek mainstream parties which avoid evaluations in $80 \%$ (ND) and close to $70 \%$ (Syriza) of their EU-related press releases.

Our results thus confirm that catch-all parties with strong internal dissent are prone to choose adoption or blurring strategies (H2b). The data show that both strategies are employed. Adoption strategies thereby do not refer to a black-white divide between expert judgements and party communication, but rather to a gradual deviation. Among the strongly divided proEuropean catch-all parties, there are only two (PS, France; PvdA, NL) that neither use blurring nor adoption strategies. However, as shown before, these parties also tend towards silencing on the topic dimension. In contrast, among united catch-all parties, adoption and blurring strategies are rare-with the Greek ND being the only exception. 
Variations in countries' politicization as a result of parties'strategies

How do parties' strategies regarding topics, issues and positions affect a country's politicization? Figure 4 summarizes our results on the country level. Regarding the first politicization dimension, topic salience, the figure shows that in all of the examined countries, parties communicate about Europe. The average EU salience on the country level ${ }^{6}$ varies between 25 percent (UK) and 56 percent (PT). Not surprisingly, in those countries where silencing strategies of (some) pro-EU catch-all parties (grey shading) are most pronounced, we find the lowest average salience (GER, GR, F, UK). In the Netherlands, it seems that moderate silencing tendencies of catch-all parties are partially compensated by the other parties. Finally, countries where pro-EU catch-all parties do not follow silencing strategies tend to have higher salience values (PT, AT, black shading) —with Portugal standing out in particular.

Regarding the issue focus, our results reveal that in two of our countries (GER, NL) pro- and anti-European parties talk past each other (triangle, Fig. 4), whereas in the other countries similar issue foci are employed (diamond, Fig. 4). This similar issue focus leads to a common debate among all parties in Portugal, Austria and Greece, whereas in the UK and France, it is catch-all parties that — despite their silencing strategies — employ issue emphasis similar to the Eurosceptics in their sparse communication, whereas smaller pro-EU parties emphasize their own EU-related issues.

Looking at these two aspects, we judge Portugal as the most politicized country regarding EU integration. However, our third politicization dimension, which deals with the range of positions formulated, reveals another picture (y-axis). We find the broadest range in the United Kingdom (range 1.2 out of a maximum of 2) and France (range 1.0) and the lowest in Portugal (0.27), followed by Germany (0.69), Greece (0.7), Austria (.81) and the Netherlands (0.95). However, the range alone does not tell us whether we can observe clear-cut positions 
supporting or contradicting the EU or whether parties offer only more or less EU-friendly (EU-critical) information. In most of the countries in our sample, contrasting positions are voiced (see Figure 3) — especially in the United Kingdom and France where we find clear-cut pro- and anti-EU positions. There is also a second group of countries where we find dissimilar evaluations; however, in these countries either the supportive or critical side avoids extreme positions (NL: -0.69 to 0.27 ; AT: -0.27 to 0.54 ). The remaining three countries tend to have a one-sided debate (PT, GR, GER, indicated by the ' 1 ' in Figure 4). This becomes most visible in Portugal where all parties more or less support EU integration. To a lesser degree, this is also the case in Germany where only the newly founded right-wing AfD and the Linke formulate moderate EU opposition $(-0.13 ;-0.14)$. In Greece, in contrast, we find a one-sided debate that extends into the Eurosceptic side (GR: -0.5 to 0.2 ).

Looking at all three politicization dimensions at the same time uncovers a noticeable relationship. It is not only that we fail to find high salience, common debates between pro- and antiEU parties and strong opinion polarization in any of the examined countries, but it seems that at least two of these politicization dimensions contradict each other in the light of parties' strategies: high salience is accompanied by low opinion polarization, whereas low salience is found in systems with party conflict. The strength of this relation is shown by the regression line in Figure 4 which explains 63 percent of the variance that we observe between countries. Taking this finding into account, we regard Austria as the most politicized country in our sample, although it does not lead on all dimensions. It shows the second highest average salience, no silencing strategies of pro-EU parties, a common debate among pro- and anti-EU parties and a moderate level of opinion polarization. All other countries miss out on at least one of the politicization dimensions: catch-all parties in the United Kingdom and France fail to make the topic of Europe visible and partly adhere to adoption or blurring strategies; parties in Portugal do not voice diverging positions; those in Greece tend to produce a low-salience, 
one-sided debate and those in the Netherlands talk past each other issue-wise. It is only in Germany that no indicator points towards politicization: low salience is combined with a divided issue focus and a one-sided debate.

\# Figure 4 about here \#

\section{Conclusion}

Pro-European parties' communication in the face of a Eurosceptic challenge has four characteristics. First, with the exception of Germany, we find that pro-European parties as such do not differ (anymore) from Eurosceptics in their willingness to attach salience to the topic of EU integration, which leads us to reject Hla. However, it is specific pro-European partiesnamely catch-all parties facing internal dissent - that have opted for silencing strategies (see the UK, France and, to a lesser degree, the Netherlands and Greece), which supports $H 1 b$. In these countries, mobilization on EU-related topics occurs, although catch-all parties do not or hardly get involved.

Second, pro-European parties in general do not shy away from discussing issues similar to those discussed by Eurosceptics, with the exception of Germany and the Netherlands where we find distinct issue foci between pro- and anti-EU parties. This similarity of issue focus is most pronounced in Austria, Greece and Portugal, where all parties campaign on the same issues. In the UK and France, it is pro-European mainstream parties (if they speak up at all) and Eurosceptics that converge issue-wise, while smaller pro-European parties diverge. Third, pro-European parties largely choose hold over adoption strategies (support for $H 2 a$ ). However, it is once again catch-all parties with strong internal dissent that are prone to choose adoption and blurring strategies, which supports $H 2 b$. Fourth, our results show that silencing and adoption / blurring strategies go hand in hand - most strongly affecting catch-all parties fac- 
ing internal dissent: if parties choose silencing strategies, they are more likely to also apply adoption or blurring strategies in their sparse communication, one of the most vivid examples being the Conservatives in France (UMP).

Our research has shown that party strategies shape politicization within each country. Our findings thus point to a noticeable relationship: the higher the salience of Europe within a country, the less conflictual is party communication. In countries where clear-cut EU evaluations are formulated, the topic of Europe is pushed to the margins. Taking this relationship into account, it is not that surprising that no country completely fulfils all dimensions of politicization. There is only one country that scores high on all dimensions: Austria. Germany occupies the opposite position as we do not find indications for politicization on any dimension for Germany.

Has the Eurosceptic challenge been taken up by pro-European parties or have the challengers themselves already won the struggle? Our evaluation is mixed. On the one hand, we see that internally divided pro-European catch-all parties in major EU countries (namely UMP, PS in France; Syriza in Greece; PvdA and VVD in the Netherlands and Conservatives and Labour in the UK) do not only avoid talking about Europe but also mostly obscure their EU positions or adopt part of the Eurosceptic rhetoric. This is problematic as it hampers a full-fledged debate on EU integration with pro and contra positions being voiced.

On the other hand, our results also show that not all pro-European parties shy away from the Eurosceptic challenge. In the midst of the EU's financial and debt crisis, major pro-EU parties have vigorously defended their pro-EU stances (ÖVP and SPÖ in Austria, PS and PSD-CDS in Portugal and, to a lesser degree as salience is low, CDU/CSU and SPD in Germany and PvdA in the Netherlands). 
Three caveats regarding our research need to be mentioned. First, the degree of politicization as we have conceptualized it is always a relative concept as we compare against the other countries in the sample. Such a conceptualization, however, does not answer the question regarding how much salience, topic similarity or opinion polarization is needed in order to speak of full politicization. Second, it would be helpful to extend our country sample by including, for example, Eastern European countries which might possibly follow other dynamics. Third, our approach rests on a detailed description of party strategies and the resulting politicization and, as such, cannot control for alternative explanations - be they on the party or country level.

Our study opens up at least two paths for future research. First, as our research has shown that there is not a uniform response to the Eurosceptic challenge on the side of pro-European parties, future research needs to increase our understanding of pro-European parties' strategic choices. We have thereby focussed on the (vote-wise) most important parties in each country, i.e. the catch-all parties. However, research needs to also take into account the smaller proEuropean parties. Furthermore, more explanatory factors need to be systematically tested in order to understand variation in the strategic responses of pro-European parties. A better understanding of parties' strategic choices will increase our knowledge concerning the differences and similarities among countries regarding their politicization. Why, for example, do we find such a strong similarity between the ever-Eurosceptic United Kingdom and the classic engine of EU integration, France?

Second, we need to analyse whether and under which conditions mass media actually take up this input of parties and how they convert it into a societal debate. Our research has shown that mass media are either confronted with high salience combined with low conflict or with 
high conflict and low salience. This input contradicts the logic of mass media because conflict is a crucial driver for salience in such media (e.g. Schuck et al., 2011). Understanding the conditions of mass media's responses to parties' input is all the more important, as mass media are those who either show the elite's struggle to the average citizens or hide it from them.

\section{Funding}

This work was supported by the Swiss National Science Foundation (100017E-144592/1) and the German Science Foundation (MA 2244/5-1).

\section{Notes}

1. Research on position blurring (e.g. Rovny, 2012) focuses on obscuring one's position on specific policy issues. We have taken up this idea but search for blurring regarding the topic dimension, i.e. the evaluation of EU integration as such.

2. The search string contains the following key words: 'Europ*, europ*, EU, EP, EZB, EIB, ESM, EFSF, EFSM, EuGH, EAD, EWSA, EIF, EDSB, EWU, Troika, Frontex, FRONTEX, constitutional treaty'.

3. A detailed overview of the reliability scores is available from the authors upon request.

4. The Duncan index of dissimilarity is equivalent to the more widely used Pedersen index on electoral volatility (Pedersen, 1979). The formula is as follows:

$$
\frac{1}{2} \sum_{i=1}^{n}\left|\frac{p_{i 1}}{P_{1}}-\frac{p_{i 2}}{P_{2}}\right|
$$

where $n$ is the number of issues, $p_{i 1}$ and $p_{i 2}$ the number of EU-related press releases devoted to issue $i$ by party 1 and party 2 , and $P_{1}$ and $P_{2}$ the total number of EU-related press releases published by party 1 and party 2 . 5. The index was built as follows: 1 'Voicing of specific and general EU support (both indicators positive)'; 0.75 'Voicing of general EU support (EUEVAL: n.a. or balanced)'; 0.5 'Voicing of general EU support and specific Euroscepticism'; 0.25 'Voicing of specific EU support (INTEGEVAL: n.a. or balanced)'; -0.25 'Voicing of specific Euroscepticism (INTEGEVAL: n.a. or balanced)'; -0.5 'Voicing of general Euroscepticism and specific EU support'; -0.75 'Voicing of general Euroscepticism (EUEVAL: n.a. or balanced)'; -1 'Voicing of specific and general Euroscepticism (both negative)'.

6. Country-level salience is measured as the share of EU-related press releases of each party within a country divided by the number of parties within a country. We have not weighted this salience measure by vote share as we specifically focus on the large catch-all parties in our detailed description. 


\section{References}

Adam S (2007) Domestic adaptations of Europe: A comparative study of the debates on EU enlargement and a common constitution in the German and French quality press. International Journal of Public Opinion Research, 19(4): 409-433.

Adam S and Maier M (2016) Campaigning on or downplaying EU integration? Explaining the salience parties attach to EU matters in European Parliamentary election campaigns. In: de Vreese, C and de Brug, W (eds) (Un-)Intended Consequences of European Parliamentary Elections. Oxford: Oxford University Press, pp.148-170.

Adam S, Maier M, De Vreese C, et al. (2013) Campaigning against Europe? The role of Euroskeptic fringe and mainstream parties in the 2009 European Parliament election. Journal of Political Marketing 12(1): 77-99.

Bakker R, Edwards E, Hooghe L, et al. (2015) 2014 Chapel Hill Expert Survey. Version 2015.1. In N. U. o. N. C. Chapel Hill, Chapel Hill. (Ed.). Available at: http://chesdata.eu/ (accessed 10 September 2015).

Bale T, Green-Pedersen C, Krouwel A, et al. (2010) If you can't beat them, join them? Explaining social democratic responses to the challenge from the populist radical right in Western Europe. Political Studies 58(3): 410-426.

Borgatti SP, Everett MG and Johnson JC (2013) Analyzing Social Networks. London: Sage.

Budge I and Farlie DJ (1983) Explaining and Predicting Elections: Issue Effects and Party Strategies in Twenty-Three Democracies. London / Boston / Syndney: George Allen \& Unwin.

Carmines EG and Stimson JA (1993) On the evolution of political issues. In: Riker WH (ed.) Agenda Formation. Ann Arbor: University of Michigan Press, pp. 151-168. 
De Sio L and Weber T (2014) Issue yield: A model of party strategy in multidimensional space. American Political Science Review 108(4): 870-885.

De Wilde P (2011) No polity for old politics? A framework for analyzing the politicization of European integration. Journal of European Integration 33(5): 559-575.

Downs A (1957) An Economic Theory of Democracy. New York: Harper.

Duncan OD and Duncan B (1955) A methodological analysis of segregation indexes. American Sociological Review 20(2): 210-217.

Ferrara F and Weishaupt J (2004) Get your act together: Party performance in European Parliament elections. European Union Politics 5(3): 283-306.

Gabel M and Scheve K (2007) Mixed messages. Party dissent and mass opinion on European integration. European Union Politics 8(1): 37-59.

Green-Pedersen C (2007). The growing importance of issue competition: The changing nature of party competition in Western Europe. Political Studies 55(3): 607-628.

Green-Pedersen C (2011) A giant fast asleep? Party incentives and politicization of European integration. Political Studies 60(1): 115-130.

Green-Pedersen C and Mortensen PB (2010) Who sets the agenda and who responds to it in the Danish parliament? A new model of issue competition and agenda-setting. European Journal of Political Research 49(2): 257-281.

Green J and Hobolt SB (2008) Owning the issue agenda: Party strategies and vote choices in British elections. Electoral Studies 27(3): 460-476.

Hobolt S and Spoon JJ (2012). Motivating the European voter: Parties, issues and campaigns in European Parliament elections. European Journal of Political Research 51(6): 701727. 
Hooghe L and Marks G (2008) A postfunctionalist theory of European integration: From permissive consensus to constraining dissensus. British Journal of Political Science 39(1): 1-23.

Hurrelmann A, Gora A and Wagner A (2013) The politicization of European integration: More than an elite affair? Political Studies 63(1): 1-17.

Hutter S and Grande E (2014) Politicizing Europe in the national electoral arena: A comparative analysis of five West European countries, 1970-2010. Journal of Common Market Studies 52(5): 1002-1018.

Koopmans R and Statham P (eds.). (2010) The Making of a European Public Sphere. Cambridge: Cambridge University Press.

Kriesi H (2008) Rejoinder to Liesbet Hooghe and Gary Marks, 'A postfunctional theory of European integration: From permissive consensus to constraining dissensus'. British Journal of Political Science 39(1): 221-224.

Kriesi H, Grande E, Lachat R, et al. (2008) West European Politics in the Age of Globalization. Cambridge: Cambridge University Press.

Maier M, Adam S, de Vreese C, Leidecker-Sandmann M, Eugster B, Schmidt F, AntlWittenberg, E (2014) Politicization of EU integration. Codebook for a content analysis of media and party communication. Available at: http://www.ikmb.unibe.ch/codebuch_eu2014.

Meguid BM (2005) Competition between unequals: The role of mainstream party strategy and nich party success. American Political Science Review 99(3): 347-360.

Parsons C and Weber T (2011) Cross-cutting issues and party strategy in the European Union. Comparative Political Studies 44(4): 383-411. 
Pedersen M (1979) The dynamics of European party systems: Changing patterns of electoral volatility. European Journal of Political Research 7(1): 1-26.

Petrocik JR (1996) Issue ownership in presidential elections, with a 1980 case study. American Journal of Political Science 40(3): 825-850.

Rovny J (2012) Who emphasizes and who blurs? Party strategies in multidimensional competition. European Union Politics 13(2): 269-292.

Schuck A, Exzonakis G, Elenbaas M, Banducci S and De Vreese C (2011) Party contestation and Europe on the news agenda: The 2009 European Parliamentary elections. Electoral Studies 30: 41-52.

Sigelman L and Buell EH (2004) Avoidance or engagement? Issue convergence in U.S. presidential campaigns, 1960-2000. American Journal of Political Science 48(4): $650-661$.

Steenbergen MR and Scott DJ (2004) Contesting Europe? The salience of European integration as a party issue. In: Marks G and Steenbergen MR (eds.) European Integration and Political Conflict. Cambridge: Cambridge University Press, pp. 165192.

Stetka V, Lilleker DG, Tenscher J and Jalali C (2014) Professional campaigning online: The role of new media as campaign platforms. Paper presented at the ECPR, Glasgow.

Van de Wardt M, De Vries CE and Hobolt SB (2014) Exploiting the cracks: Wedge issues in multiparty competition. The Journal of Politics 76(4): 986-999.

Van der Eijk C and Franklin MN (2004) Potential for contestation on European matters at national elections in Europe. In: Marks G and Steenbergen MR (eds.) European Integration and Political Conflict. Cambridge: Cambridge University Press, pp. 3250. 
Van Noije L, Kleinnijenhuis J and Oegema D (2008) Loss of parliamentary control due to mediatization and Europeanization: A longitudinal and cross-sectional analysis of agenda building in the United Kingdom and the Netherlands. British Journal of Political Science 38(3): 455-478. .

Williams C and Spoon JJ (2015) Differentiated party response: The effect of Eurosceptic public opinion on party positions. European Union Politics 16(2): 176-193. 
Figures and Tables

\begin{tabular}{|l|l|l|}
\hline Topic & Issue \\
\hline Silencing & Position \\
\hline Agenda-building & Similar issue emphasis & Sinct issue emphasis \\
\hline
\end{tabular}

Figure 1. Pro-EU parties's strategic repertoire. 


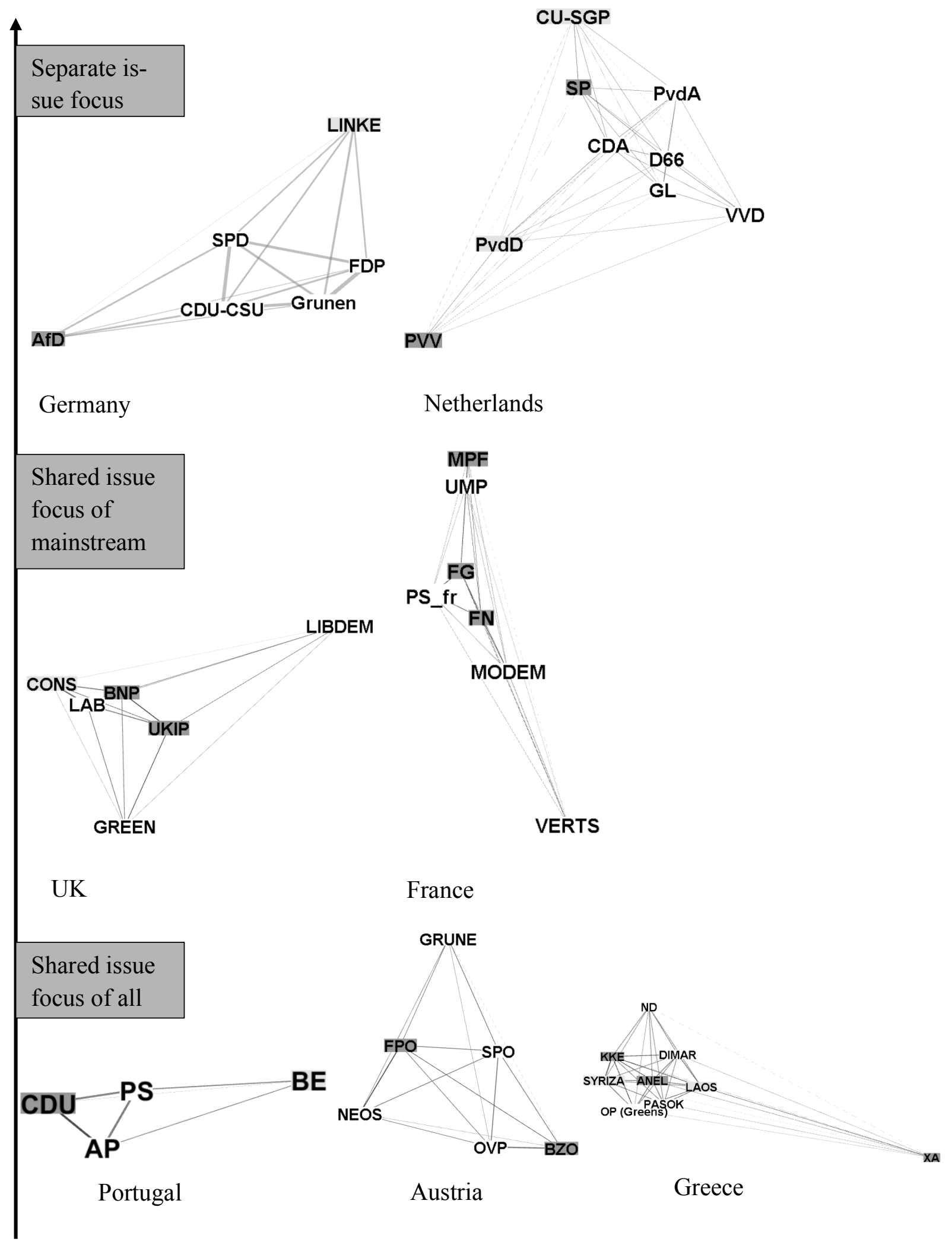

Figure 2. The relation between pro-EU and anti-EU parties regarding their issue focus.

Note: Network visualization based on Force Atlas II, Gephi (Scaling: 1.00000; Edge Weight: 7);

Colours: dark grey $=$ Eurosceptics $($ EU position $<3)$, light grey $($ EU position $\geq 3$ and $\leq 5)$; white $=$ pro-European

Basis: EU positions (Bakker et al., 2015), Duncan index (issue distribution from the author's own study) 


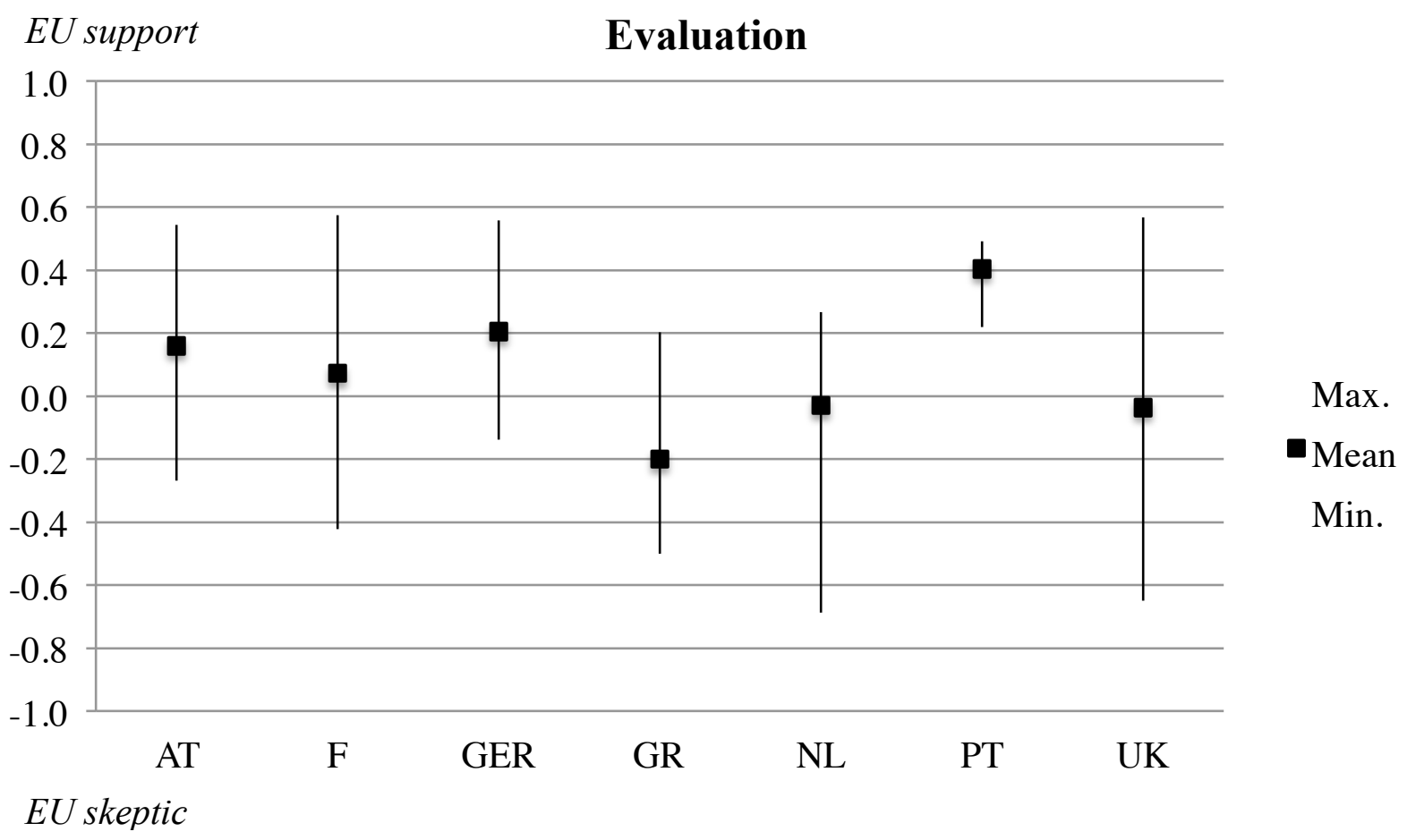

Figure 3. Range of opinions towards EU integration in parties' press releases.

Basis: press releases with an EU evaluation; $\mathrm{N}(\mathrm{AT})=530 ; \mathrm{N}(\mathrm{F})=120 ; \mathrm{N}(\mathrm{GER})=175 ; \mathrm{N}(\mathrm{GR})=201 ; \mathrm{N}(\mathrm{NL})=120 ; \mathrm{N}$ $(\mathrm{PT})=231 ; \mathrm{N}(\mathrm{UK})=142$ 


\section{Opinion Polarization (range)}

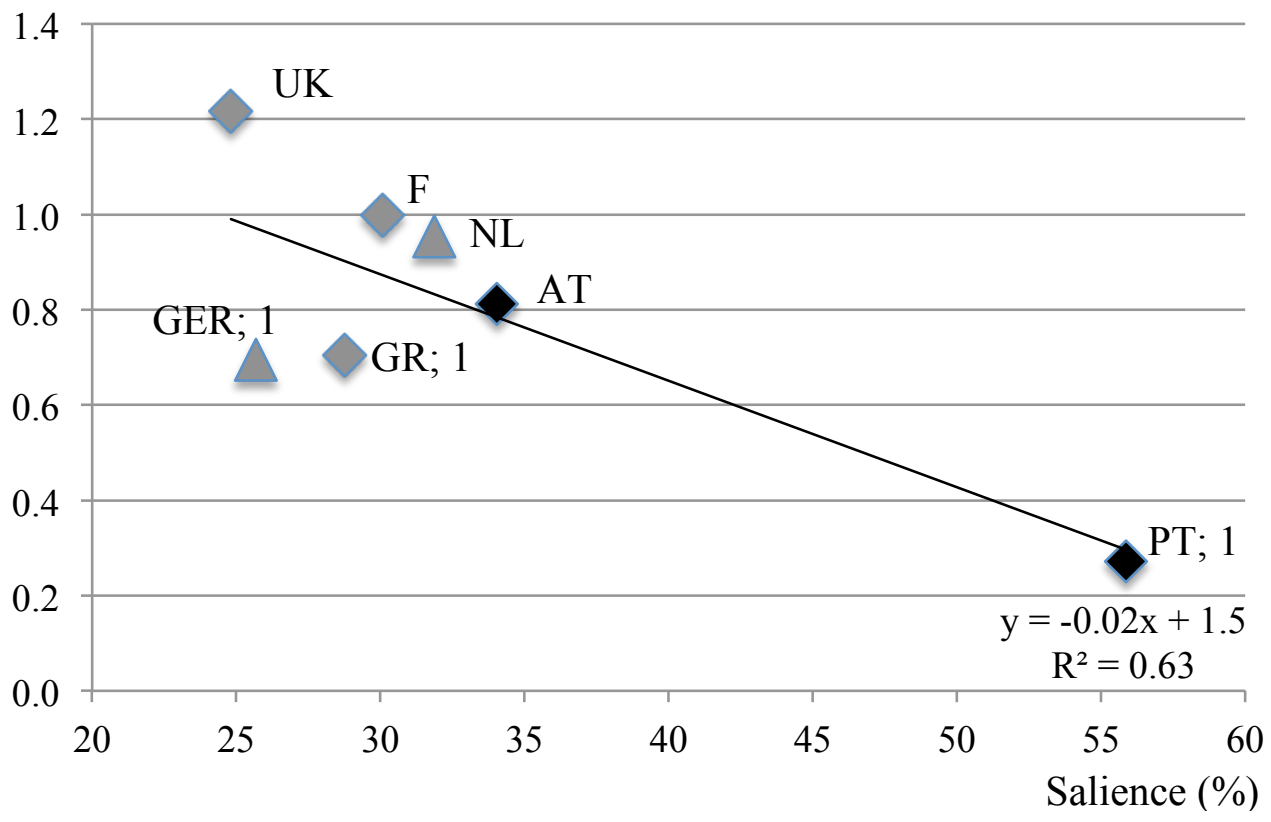

\section{Figure 4. Degree of Politicization.}

Note: Topic (1) x-axis (average share of EU-related press releases); (2) grey shading = silencing strategies of (some) pro-EU catch-all parties; black = no silencing strategies of pro-EU catch-all parties; Issue: diamond = common debate; triangle = divided debate; Position: (1) y-axis (range of opinions within a country); $1=$ one-sided debate with either pro or contra positions dominating; Regression model: Relationship between opinion polarization and salience explains 63 percent of the variance. 
Table 1. Distinct topic strategies of pro-European parties?

\begin{tabular}{lcc}
\hline & Pearson r & Significance \\
\hline Austria & -0.13 & n.s. $(0.27)$ \\
France & -0.03 & n.s. $(0.46)$ \\
Germany & 0.64 & $*(0.04)$ \\
Greece & 0.05 & n.s. $(0.28)$ \\
Netherlands & -0.14 & n.s. $(0.21)$ \\
Portugal & 0.10 & n.s. $(0.30)$ \\
UK & -0.25 & n.s. $(0.10)$ \\
\hline
\end{tabular}

Note: QAP correlations ( $\Delta$ salience $[0 ; 1=$ large difference]; $\Delta$ EU position $[0 ; 6=$ large difference $]$ ).

Basis: EU positions (Bakker et al., 2015), salience: share of EU related press releases / all press releases (own study).

Significance level: n.s. $=$ not significant; $\dagger \mathrm{p}<.1 ;{ }^{*} \mathrm{p}<.05 ; * * \mathrm{p}<.01$. 
Table 2. Distinct issue foci of pro-European parties?

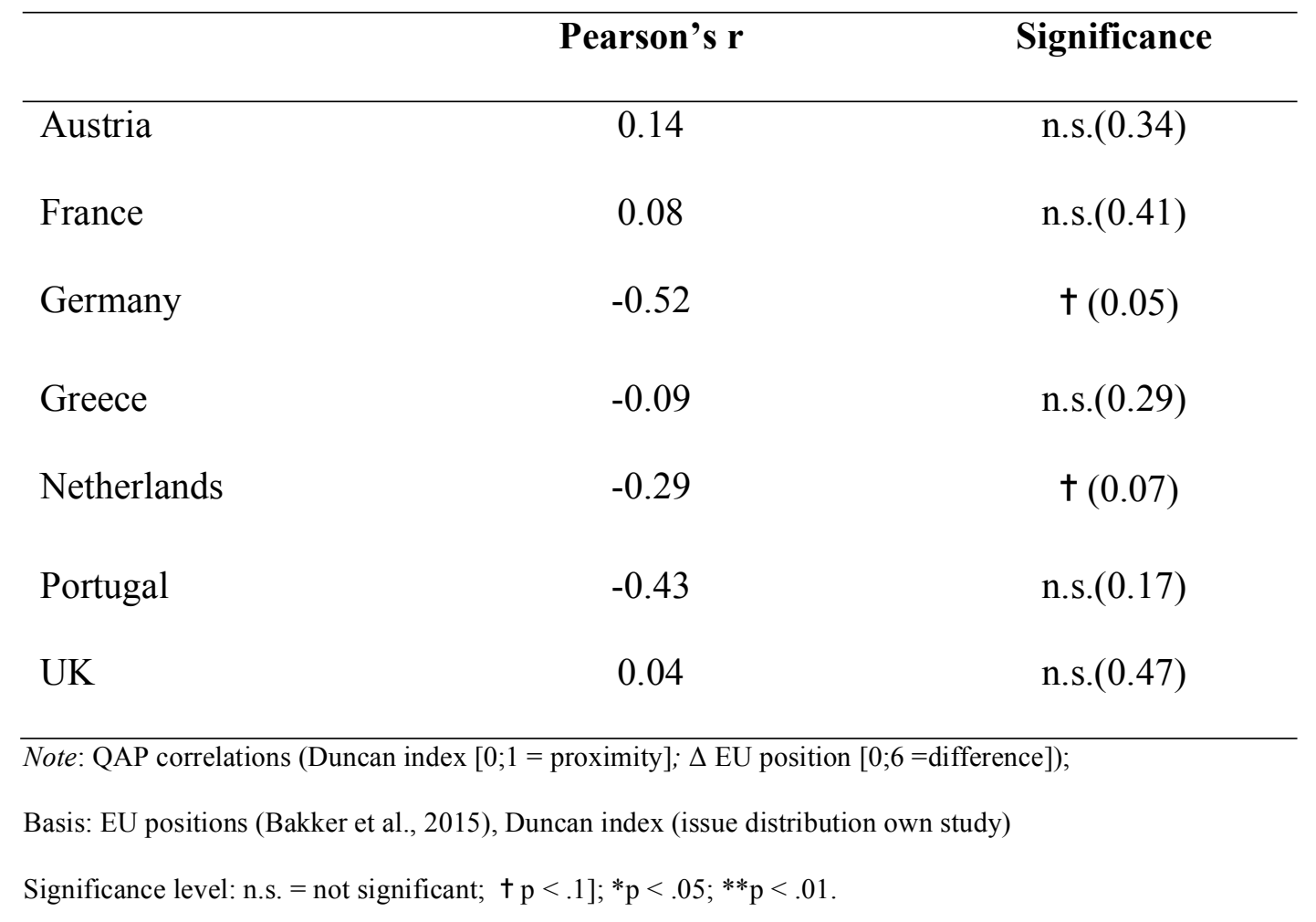


Table 3. Distinct position strategies of pro-European parties?

\begin{tabular}{lcc}
\hline & Pearson's r & Significance \\
\hline Austria & 0.71 & $*(0.04)$ \\
France & 0.79 & $*(0.03)$ \\
Germany & 0.72 & $*(0.04)$ \\
Greece & 0.61 & $* *(0.00)$ \\
Netherlands & 0.79 & $* *(0.00)$ \\
Portugal & -0.40 & $* *(0.00)$ \\
UK & 0.74 & $*(0.01)$ \\
\hline Note: QAP correlations $(\Delta$ EU evaluation in press releases $[0 ; 2=$ difference]; $\Delta$ EU position $[0 ; 6=$ difference $]$; \\
Basis: EU positions $(C H E S$, Bakker et al., 2015$)$, evaluations in press releases $($ own study $)$
\end{tabular}

